a Universidade Federal de Viçosa. Departamento de Química, Avenida PH Rolfs s/n, Campus Universitário, CEP 36570-000, Viçosa - MG, Brasil ${ }^{\mathrm{b}}$ Universidade Federal de Viçosa. Departamento de Tecnologia de Alimentos, Avenida PH Rolfs, s/n, Campus Universitário, CEP 36570-000, Viçosa-MG, Brasil

\section{*E-mail: jose.lafeta@ufv.br}

Recebido em: 16 de Novembro de 2020

Aceito em: 22 de Julho de 202

Publicado online: 16 de Novembro de 202

\section{Efeito da Temperatura Sobre a Separação e Purificação de Proteínas do Soro de Leite Utilizando Sistemas Aquosos Bifásicos}

\author{
Effect of Temperature on the Separation and Purification of Whey \\ Proteins Using Aqueous Two-Phase Systems
}

José Antônio de Queiroz Lafetá Junior, ${ }^{a, *}$ Matheus Furlan Pinheiro, ${ }^{a}$ Cariny Maria Polesca, ${ }^{a}$ Rita de Cássia Superbi, ${ }^{(10}$ Jane Sélia dos Reis Coimbrab

\begin{abstract}
The present review work presents studies aimed at the recovery of $\alpha$-lactalbumin, $\beta$-lactoglobulin, bovine serum albumin and glycomacropeptide, proteins present in milk whey, using Biphasic Aqueous Systems (SAB's). SAB's have been presented as an alternative for liquid-liquid separation, with good separation efficiency and reduced use of toxic organic diluents. The search for the optimization of these processes has been the focus of studies, with the temperature being a significant variable. This review had the main objective of synthesize the scientific discoveries on the relation of Extraction Efficiency $\mathrm{x}$ System Temperature, for protein extraction with SAB's constituted by Polymer-Polymer, Polymer-Salt and Ionic Liquid-Salt.
\end{abstract}

Keywords: $\alpha$-Lactalbumin; $\beta$-lactoglobulin; bovine serum albumin; glycomacropeptide

\section{Introdução}

O soro corresponde à parte aquosa que permanece após a coagulação do leite, uma das etapas da produção do queijo, apresentando cerca de $55 \%$ dos nutrientes do leite. ${ }^{1}$ É considerado um subproduto, que se não for tratado de forma adequada torna-se um poluente ambiental, devido aos altos volumes produzidos e ao seu elevado teor de matéria orgânica e sal. A valorização do soro pode ser realizada a partir da recuperação dos principais componentes presentes com alto valor agregado, como proteínas solúveis ou lactose. ${ }^{2}$

Entre as proteínas presentes no soro de leite, a $\alpha$-lactalbumina $(\alpha$-lc) e a $\beta$-lactoglobulina $(\beta-\lg )$ possuem destaque, pois estão presentes em quantidades significativas (superiores a $50 \%$ do total). ${ }^{1,3}$ Entre as demais proteínas, vale citar a imunoglobulina (IG) e albumina sérica bovina (BSA), ${ }^{4}$ além de uma alta fração de peptídeos e outros numerosos conteúdos proteicos menores, como o glicomacropeptídeo (GMP).,

Do ponto de vista industrial, a filtração por membrana é um método usualmente empregado para recuperação das proteínas, devido à vantagem proveniente da diferença significativa entre a massa molar da proteína e dos demais componentes presentes no soro, como gordura, lactose e sais minerais. ${ }^{2}$ Entretanto, apresenta limitações como vida útil limitada e alto custo. Nesse sentido, a extração líquido-líquido em sistemas bifásicos aquosos (SAB's) vem sendo avaliada por muitos pesquisadores,${ }^{2}$ apresentando vantagens como simplicidade de operação, ${ }^{6}$ facilidade de implementação em larga escala, separação rápida e seletiva, acelerada transferência de massa, obtenção de alta pureza e rendimento significativo. ${ }^{1}$

Os SAB's, inicialmente propostos em 1896 por Beijerinck, ${ }^{1}$ são formados por duas fases ricas em água, ${ }^{6}$ baseados na mistura de dois polímeros hidrofílicos ou um polímero e um sal inorgânico sob determinadas condições de concentração e temperatura. ${ }^{1}$ Nos dias atuais, líquidos iônicos (LI), solventes eutéticos profundos (SEP's), sacarídeos e pequenas moléculas orgânicas vêm sendo empregados na elaboração dos SAB's. ${ }^{2,6,7}$

Condições durante a hidrólise das proteínas presentes no soro de leite, como temperatura, possuem impacto significativo na cinética de reação, podendo permitir melhor controle do processo de modo que a hidrólise ocorra como desejadado. ${ }^{7}$ Dessa forma, essa revisão possui como objetivo reunir informações sobre a separação e purificação das principais proteínas solúveis (BSA, GMP, $\alpha$-lc e $\beta$-lg) presentes no soro de leite, por meio da utilização de diferentes tipos de SAB's, bem como discutir a influência da temperatura na eficiência de separação. 


\section{Proteínas Presentes no Soro de Leite}

As proteínas presentes no soro de leite são subprodutos valiosos, com alto valor nutricional, sendo amplamente utilizado como ingrediente em alimentos formulados. ${ }^{4,8}$ As proteínas possuem diversas funcionalidades biológicas (digestibilidade, antimicrobiana, antiviral e anticarcinogenica), físicas e químicas (absorção de água, gelificação, formação de espuma e emulsificação), que são essenciais em aplicações alimentares. São geralmente utilizadas como ingredientes em produtos de confeitaria, padaria, sorveteria, alimentos saudáveis e fórmulas infantis. ${ }^{4}$

Diversos produtos de soro de leite bovino são produzidos comercialmente, diferindo principalmente no conteúdo de proteína, incluindo: Concentrado proteico de soro (34-80\%), Isolado proteico de soro (90-95\%) e Proteína de soro de leite hidrolisada $(80-90 \%){ }^{8}$

Essas proteínas são tipicamente de natureza globular (muito suscetíveis à desnaturação pelo calor), com altos níveis de estruturas secundárias e terciárias nas quais os aminoácidos ácidos/básicos e hidrofóbicos/hidrofílicos são distribuídos de forma bastante equilibrada. ${ }^{4}$

As principais proteínas do soro de leite bovino são $\beta$-lg $( \pm 50 \%), \alpha$-lc $( \pm 20 \%)$, IG $( \pm 10 \%)$ BSA $( \pm 10 \%)$ e lactoferrina $(<3 \%){ }^{4,8} \mathrm{~A} \beta$-lg possui concentração relativa $\left(\mathrm{C}_{\mathrm{r}}\right)$ de $3,5 \mathrm{~g} \cdot \mathrm{L}^{-1}$, massa molecular (MM) de aproximadamente $18.300 \mathrm{~g} \cdot \mathrm{mol}^{-1}$, ponto isoelétrico (pI) de 5,2 e temperatura de desnaturação $(\mathrm{Td})$ de $71,9{ }^{\circ} \mathrm{C}$; a $\alpha$-lc apresenta $\mathrm{C}_{\mathrm{r}}$ de $1,2 \mathrm{~g} \cdot \mathrm{L}^{-1}, \mathrm{MM}$ de $14.200 \mathrm{~g} \cdot \mathrm{mol}^{-1}$, pI de 4,8 e Td de $64,3^{\circ} \mathrm{C}$; a IG possui CR de $0,7 \mathrm{~g} \cdot \mathrm{L}^{-1}$ e $\mathrm{pI}$ de $5,5-6,8$; a BSA possui $\mathrm{C}_{\mathrm{r}}$ de $0,4 \mathrm{~g} \cdot \mathrm{L}^{-1}$, MM de $66.430 \mathrm{~g} \cdot \mathrm{mol}^{-1}$, pI de 4,7-4,9 e Td de $72-74{ }^{\circ} \mathrm{C}$; a lactoferrina apresenta $\mathrm{C}_{\mathrm{r}}$ de $0,02-035 \mathrm{~g} \cdot \mathrm{L}^{-1}$, MM de $80.000 \mathrm{~g} \cdot \mathrm{mol}^{-1}$, pI de 8-8,5 e Td de $63-90{ }^{\circ} \mathrm{C} .4,8$ A lactoferrina é uma glicoproteína globular monomérica ligante de ferro, em que cada monômero de lactoferrina pode ligar 2 íons $\mathrm{Fe}^{3+}$. Essa capacidade de ligação do ferro provavelmente contribui para seu potencial antioxidante. ${ }^{8}$

O soro de leite bovino possui concentrações diluídas de imunoglobulinas [IgA, $\operatorname{IgM}$ e $\operatorname{IgG}$ (IgG1 e IgG2)], que são moléculas de estruturas quaternárias, sejam monômeros ou polímeros com 4 cadeias, consistindo em 2 cadeias polipeptídicas leves (MM $25.000 \mathrm{~g} \cdot \mathrm{mol}^{-1}$ ) e 2 cadeias pesadas (MM entre $50.000 \mathrm{e} 70.000 \mathrm{~g} \cdot \mathrm{mol}^{-1}$ ) ligadas por ligações dissulfeto. ${ }^{8}$ A IgG aparece como monômero $(\sim 160 \mathrm{kDa})$, enquanto a $\operatorname{IgA}(\sim 370 \mathrm{kDa})$ e $\operatorname{IgM}(\sim 1000 \mathrm{kDa})$ como polímero. A sua estrutura é afetada por tratamentos térmicos a partir da temperatura de $65^{\circ} \mathrm{C} .{ }^{9}$

Uma característica relevante das proteínas (particularmente das $\beta$-lg e $\alpha$-lc) é a capacidade de interação proteína-proteína, permitindo o desenvolvimento de matrizes de proteínas funcionais personalizadas com novas propriedades reológicas e emulsificantes. ${ }^{4,10}$ Diferentes tipos de interações moleculares entre as principais proteínas presentes no soro de leite foram revisados por Nicolai et al. ${ }^{11}$

\section{Utilização de Sistemas Aquosos Bifásicos para Recuperação de Proteínas do Soro do Leite}

O soro do leite é subproduto do processo de produção de queijo, com elevado valor agregado em função da presença de importantes biomoléculas em sua composição, como as proteínas. Por isso, a separação de suas proteínas desperta a atenção dos pesquisadores à tempos. ${ }^{12}$ Os primeiros métodos de separação de proteínas do soro do leite eram baseados na precipitação. Ao passar do tempo, a técnica foi perdendo espaço devido às alterações estruturais que o método promove nas proteínas e a dificuldade de se promover precipitações seletivas para fracionamento de proteínas específicas. $\mathrm{O}$ avanço da tecnologia permitiu o desenvolvimento de métodos como os processos de separação por membranas, técnicas cromatográficas e extração líquido-líquido. ${ }^{13,14}$

A extração líquido-líquido é uma operação unitária aplicável em processos de separação e purificação de compostos de diferentes naturezas. ${ }^{15-18}$ Também conhecida como extração por solvente ou partição, é aplicada para separar solutos (e.g. proteínas doso soro) de uma mistura heterogênea de líquidos baseado em suas diferentes solubilidades em dois líquidos diferentes imiscíveis, os solventes. A utilização dos clássicos sistemas de extração líquido-líquido utilizando solventes orgânicos se torna inviável para extração de proteínas, devido as possíveis mudanças estruturais causadas pelo ambiente químico da fase orgânica à biomolécula. A utilização de SAB's, um tipo de extração líquido-líquido em que as suas fases são compostas majoritariamente por água, resolve a questão, se apresentando como uma técnica rápida, pouco invasiva e eficiente. ${ }^{19}$

A partição de compostos biológicos através do SAB's é derivada das interações entre a biomolécula e as fases contínuas. Destacam-se as interações iônicas, de Van der Waals, hidrofóbicas e ligações de hidrogênio. ${ }^{20,21}$ O coeficiente de partição é a grandeza utilizada para entender a tendência do soluto em distribuir-se entre fases líquidas, podendo ser mensurado através da razão entre as concentrações ou atividades do soluto na fase superior e na fase inferior do $\mathrm{SAB}$, como mostra a equação a seguir. ${ }^{17}$

$$
K=\frac{a_{S}}{a_{I}} \cong \frac{c_{S}}{c_{I}}
$$

onde $\mathrm{a}_{\mathrm{S}}$ e $\mathrm{c}_{\mathrm{S}} \mathrm{s}$ ão, respectivamente, a atividade e a concentração do soluto na fase superior e $a_{I}$ e $c_{I}$ são, respectivamente, a atividade e a concentração do soluto na fase Inferior. A distribuição das proteínas entre as duas fases é função de um complexo equilíbrio de interações entre a proteína e as outras espécies envolvidas (polímeros, água e sais inorgânicos) presentes nas duas fases que coexistem em equilíbrio. ${ }^{22}$

Logo, o coeficiente de partição das proteínas depende de muitas variáveis, como a conformação molecular, especificidade, dimensões físicas, hidrofobicidade, além das 
condições ambientais do sistema, como a temperatura. ${ }^{20,21} \mathrm{~A}$ influência da temperatura neste processo é complexa devido ao seu efeito sobre a composição das fases em equilíbrio, nas interações entre a proteína e as fases contínuas, assim como possíveis alterações da estrutura da biomolécula. ${ }^{23}$ As mudanças na temperatura do sistema afetam também a partição das proteínas através das mudanças na viscosidade e densidade das fases. Logo, a temperatura é um parâmetro que deve ser controlado durante todo o processo de separação. ${ }^{17}$

Os SAB's se apresentam como uma alternativa de baixo custo, curto tempo de processo e de fácil escalonamento para separação das proteínas do soro do leite. ${ }^{19,24}$ De acordo com $\mathrm{Ng}$ et al. ${ }^{25}$, os SAB's possui potencial para atuar como uma técnica complementar à outros processos de separação de proteínas do soro do leite, que amortiza principalmente os custos das etapas de downstream. Rojas et al. ${ }^{26}$ reportaram a utilização do SAB's como etapa anterior à cromatografia de exclusão molecular para separação de proteínas do soro do leite, corroborando que a técnica pode ser aplicada com sinergia em conjunto com outras técnicas de separação.

SAB's, empregando fases polímero-polímero ${ }^{15,25,27-29}$, polímero-sal ${ }^{24,30-41}$ e líquido iônico-sal ${ }^{42-47}$, são aplicados com sucesso na separação e recuperação de proteínas do soro do leite. Além de vários pesquisadores que avaliaram a partição utilizando proteínas isoladas do soro do leite, existem os que partiram do soro do leite in natura, que inclusive avaliaram a influência da temperatura no processo de separação das proteínas. ${ }^{16,39,48}$

Apesar da grande quantidade de trabalhos focados na separação das proteínas do soro, os SAB's também podem auxiliar na separação de outros compostos importantes, auxiliando de forma indireta na separação das proteínas. Anandharamakrishnan et al..$^{27}$ compararam a utilização de sistemas polímero-polímero e polímero-sal para concentração das proteínas do soro do leite e separação da fase lipídica, também partindo do soro in natura. Seus resultados mostram que as fases polímero-sal (polietilenoglicol 6000/fosfato de potássio) ofereceu o melhor coeficiente de partição, onde as proteínas tendem a se concentrar na fase superior (polimérica) e a gordura na fase inferior (salina), em concordância com os resultados apresentados por Chen..$^{39}$ Métodos utilizados com frequência na separação e concentração de proteínas do soro do leite, como os processos de separação por membrana e cromatografia, apresentam problemas de incrustações relacionadas a presença de gordura residual no soro do leite, ${ }^{49,50}$ mostrando mais uma vez o potencial que os SAB's possuem para complementar e auxiliar nos processos de separação do soro do leite.

A lactose é outro componente presente no soro do leite que limita processos de separação e a utilização do soro do leite em pó como ingrediente. Domínguez-Puerto et al. ${ }^{51}$ avaliaram a utilização de poli(etilenoglicol) (PEG) 4000 e sulfato de amônio na separação das proteínas do soro e lactose do soro in natura, apresentando recuperação máxima de proteína e eliminação da lactose de $93,0 \%$ e $72,3 \%$ respectivamente. Além disto, o processo concentra as proteínas do soro em até 2,45 vezes, sem custos energéticos.

Esses e outros trabalhos mostram que SAB's possuem grande potencial para aplicação na recuperação de proteínas do soro do leite em sistemas reais; principalmente devido aos pontos positivos que oferecem, como ambientes suaves o suficiente para preservar a funcionalidade das biomoléculas, fácil aumento de escala, rápida transferência de massa e obtenção do equilíbrio, técnica versátil e adaptável, economicamente viável ${ }^{52}$, simplicidade de operação ${ }^{6}$, utilização da temperatura ambiente ${ }^{53}$, obtenção de alta pureza e rendimento significativo. ${ }^{1}$ No entanto, para colocar em prática essas ideias é necessário ir além da escala laboratorial e modo batelada presentes na literatura, direcionando os esforços para problemas como o escalonamento do processo e a adequação de modos operacionais contínuos, como os trabalhos de Coimbra et al. ${ }^{35}$, Vázquez-Villegas et al. ${ }^{54} \mathrm{e}$ Kalaivani e Regupathi ${ }^{33}$.

Dentre os diferentes fatores que podem influenciar na seletividade de partição das proteínas, daremos ênfase em trabalhos que avaliaram a influência da temperatura. A seguir são abordadas pesquisas encontradas na literatura, que abordam a separação de proteínas do soro de leite e o efeito da temperatura em três combinações diferentes de componentes formadores de fases: (i) Polímero-Sal; (ii) Polímero-Polímero e (iii) Líquido Iônico-Sal.

\subsection{SAB's Polímero - Sal}

Dentre as combinações de fases aplicadas às proteínas do soro do leite, a combinação polímero-sal é a que possui maior número de trabalhos que relacionam o efeito da temperatura sobre o coeficiente de partição (Tabela 1).

O efeito da temperatura pode variar de acordo com os tipos das fases, refletindo em comportamentos diferentes. Segundo Walter ${ }^{61}$, de maneira geral, a separação de fases é alcançada utilizando baixas temperaturas em sistemas polímero-polímero, em contraste com o que é observado para sistemas polímero-sal. A hidrofobicidade das fases poliméricas é aumentada em função do incremento da temperatura, favorecendo a interação entre suas moléculas e, consequentemente, diminui sua interação com moléculas de água. ${ }^{23}$

Mohan et al. ${ }^{16}$ avaliaram o efeito de diferentes temperaturas $\left(30-80{ }^{\circ} \mathrm{C}\right)$ sobre a partição de proteínas do soro do leite usando PEG 4000 e sulfato de sódio. Seus resultados apontam que em concentração de $50 \%$ da fase polimérica, $40 \%$ da fase salina, $\mathrm{pH}$ 5,4 e temperatura de $35{ }^{\circ} \mathrm{C}$ apresentou maior coeficiente de partição. Em temperaturas acima de $35{ }^{\circ} \mathrm{C}$ o coeficiente de partição apresentou diminuição progressiva. Os autores sugerem que o motivo é a consequente alteração da composição das fases, onde o incremento da temperatura favorece a concentração do polímero na fase superior e de sal na 
Tabela 1. Efeito da temperatura na separação de proteínas do soro do leite em SAB's com combinação de fases Polímero-Sal Polímero - Sal

\begin{tabular}{cccccc}
\hline Proteínas & Componentes & T $\left({ }^{\circ} \mathbf{C}\right)$ & Efeito $\uparrow \mathbf{T}$ & pH & Referências \\
\hline BSA & PEG 2000 e citrato de sódio & 25,35 e 45 & $\downarrow \mathrm{K}$ & $5,0-9,0$ & 55 \\
BSA & PEG 6000 e citrato de sódio & $15,25,35$ e 45 & $\downarrow \mathrm{K}$ & 8,5 & 56 \\
BSA & PEG 4000 e citrato de sódio & 35 e 45 & $\uparrow \mathrm{K}$ & $5,2-9.2$ & 57 \\
Soro do Leite & PEG 8000 e fosfato de potássio & 7,25 e 40 & $\uparrow \mathrm{K}$ & 4,5 & 39 \\
Soro do Leite & PEG 2000 e citrato de sódio & 25,35 e 45 & $\downarrow \mathrm{K}$ & - & 48 \\
Soro do Leite & PEG 4000 e sulfato de sódio & $30-80$ & $\downarrow \mathrm{K}$ & 5,4 & 16 \\
GMP & PEG 1500 e citrato de sódio & 25 e 45 & $\uparrow \mathrm{K}$ & 8,0 & 32 \\
$\alpha$-lc e $\beta$-lc & PVP e fosfato de potássio & $10-40$ & $\uparrow \mathrm{K}$ & 8,2 & 36 \\
$\alpha$-lc e $\beta$-lc & PEG 1000 e citrato de sódio & $15-50$ & $\uparrow \mathrm{K}$ & - & 58 \\
$\alpha-$ lc & PEG 1000 e citrato tripotássico & 25,30 e 35 & $\downarrow \mathrm{K}$ & - & 59 \\
GMP & PEG 1500 e citrato de sódio & $5-45$ & $\uparrow \mathrm{K}$ & 8,0 & 60 \\
\hline
\end{tabular}

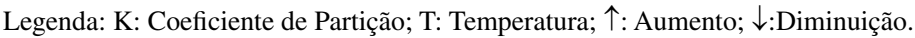

fase inferior. Além disso, dentro da faixa de temperatura estudada, o incremento da temperatura pode levar a desnaturação de algumas proteínas do soro do leite, afetando suas estruturas secundárias e terciárias, e consequentemente sua solubilidade e coeficiente de partição.

Muitos estudos são realizados com o objetivo de quantificar e explicar o comportamento de desnaturação das proteínas. Conforme citado por Hamborg et al. ${ }^{62}$, as estabilidades das proteínas são comumente determinadas pela mudança gradual da temperatura. A pesquisa de Haque et al. ${ }^{63}$ mostra que a temperatura de desnaturação de proteína isolada do soro de leite é de $70{ }^{\circ} \mathrm{C}$. No entanto, a desnaturação pode ocorrer mesmo em temperaturas inferiores, devido à desidratação e tensões relacionadas à interface; tal como pode ocorrer em temperaturas superiores, devido a tensões térmicas e desidratação.

Silva et al..$^{32}$ estudaram a influência da temperatura na partição de GMP em PEG 1500 e citrato de sódio, apresentando uma recuperação de $85 \%$ da proteína na fase leve (polimérica) e demostrando a potencialidade do uso do processo como um ponto para se iniciar a separação de GMP do soro do leite. Foram avaliadas temperaturas entre $25 \mathrm{e}$ $45^{\circ} \mathrm{C}$, obtendo resultados que indicam que o incremento da temperatura é capaz de aumentar o coeficiente de partição do GMP. Assim como no trabalho de Mohan et al. ${ }^{16}$, o incremento da temperatura favoreceu a concentração do polímero na fase superior e de fase salina na fase inferior, fenômeno que pode ser explicado através de conceitos que relacionam o efeito da temperatura e a inclinação das linhas de amarração. De acordo com Carvalho et al. ${ }^{64}$ a inclinação das linhas de amarração tende a aumentar com o incremento da temperatura, reduzindo a quantidade de sal necessária para a formação do sistema bifásico em determinada concentração de polímero. Pode-se concluir que o GMP apresenta um maior coeficiente de partição em função do incremento da temperatura, devido a sua preferência pela fase polimérica, resultados que estão em concordância aos apresentados por Silva et al. $^{60}$
Relevante ressaltar que apesar de Mohan et al. ${ }^{16} \mathrm{e}$ Silva et al. ${ }^{32}$ observarem a concentração da fase polimérica e salina em função da temperatura, obtiveram resultados contrastantes em relação ao coeficiente de partição das proteínas. A teoria apresentada por Mohan et al. ${ }^{16}$ sugere que o aumento da concentração da fase polimérica ou da massa molar do polímero induz a diminuição da solubilidade das proteínas na fase que ela seria enriquecida. Spelzini et al. ${ }^{65}$ reporta que a interação entre a fase polimérica, fase salina e proteínas prevalece sobre o efeito da exclusão da água que solvatam as proteínas, em concordância com Saravanan et al. ${ }^{66}$, que afirmam que quanto maior a concentração da fase polimérica, maior o número de unidade poliméricas envolvidas na partição das proteínas, e consequentemente, maior o número de moléculas de proteínas na fase polimérica, devido a interação hidrofóbica entre elas.

Perumalsamy e Batcha ${ }^{56}$ investigaram a partição da BSA em PEG 6000 e citrato de sódio nas temperaturas de 15 a $45^{\circ} \mathrm{C}$. Foi observado que o coeficiente de partição diminui com o incremento da temperatura. Esse comportamento também foi visualizado por Perumalsamy e Murugesan ${ }^{55}$ utilizando PEG 2000 e citrato de sódio nas temperaturas 25, 35 e $45^{\circ} \mathrm{C}$. Apesar de estudarem as mesmas proteínas e sal (citrato de sódio), os trabalhos citados acima observaram comportamento diferente em relação ao trabalho de Muthiah e Pampana ${ }^{57}$ para o coeficiente de partição e aumento da temperatura. Muthiah e Pampana observaram o incremento do coeficiente de partição em função do aumento da temperatura utilizando dessa vez o PEG 4000. Mesmo considerando as diferenças de condições, como pH e concentração de do sal, os três trabalhos justificaram o efeito da temperatura com base na alteração da estrutura polimérica (PEG) causada pelas alterações da temperatura.

Além da hidrofobicidade, outras alterações na fase polimérica causadas pela variação da temperatura afetam o coeficiente de partição das proteínas do soro do leite. Mokhtarani et al. ${ }^{36}$ estudaram a influência da temperatura (10- 
$40^{\circ} \mathrm{C}$ ) na partição da $\alpha$-lc e $\beta$-lc, utilizando polivinilpirrolidona e fosfato de potássio. Os resultados experimentais mostram que a $\alpha$-lc tende a concentrar na fase polimérica e $\beta$-lc na fase salina, em concordância com os resultados de Coimbra et al. ${ }^{35}$ utilizando PEG e fosfato de potássio e Rodrigues et al. ${ }^{68}$ utilizando PEG e sulfato de amônia. ${ }^{35,68}$ De acordo com Mokhtarani et al.,$^{36}$ a diminuição da viscosidade da fase polimérica em função do incremento da temperatura favorece a transferência de massa das proteínas e, consequentemente, o aumento do coeficiente de partição.

Os resultados apresentados por Mokhtarani et al. ${ }^{36}$ mostram que o impacto da temperatura sobre o coeficiente de partição da $\alpha$-lc é superior ao da $\beta$-lg. Sivakumar e Iyyaswami ${ }^{58}$, de maneira semelhante, avaliam o efeito da temperatura $\left(15-50{ }^{\circ} \mathrm{C}\right)$ sobre a partição de $\alpha$-lc e $\beta$-lg, mas usando PEG 1000 e citrato de sódio como fases. Em concordância com os resultados apresentados por Mokhtarani et al. ${ }^{36}$ o coeficiente de partição da $\alpha$-lc aumenta linearmente com o incremento da temperatura, até atingir os $40^{\circ} \mathrm{C}$, enquanto o coeficiente de partição da $\beta$-lg aumenta de maneira atenuada.

Para explicar a maior sensibilidade e mudança de comportamento do coeficiente de partição da $\alpha$-lc a partir dos $40{ }^{\circ} \mathrm{C}$, pode-se recorrer às mudanças estruturais da proteína em função da temperatura. Entre 25 e $45{ }^{\circ} \mathrm{C}$, a $\alpha$-lc passa de seu estado nativo para o estado globular fundido, onde a temperatura afeta parcialmente as estruturas terciárias da $\alpha$-lc, mantendo suas estruturas secundárias intactas, apresentando estados intermediários antes de atingir os $45^{\circ} \mathrm{C} .{ }^{69} \mathrm{Em}$ seu estado globular fundido a $\alpha$-lc é capaz de se ligar a 270 moléculas de água e suas regiões hidrofóbicas não se encontram regularmente empacotadas no interior do glóbulo. ${ }^{70}$ Em temperaturas superiores, mudanças nas estruturas terciárias e exposição de grupos hidrofóbicos podem não favorecer as interações hidrofóbicas entre a fase polimérica e a $\alpha$-lc e consequentemente $o$ coeficiente de partição diminui em temperaturas próximas e acima de $45^{\circ} \mathrm{C}$. Resultados apresentados por Sivakumar e Iyyaswami ${ }^{59}$, avaliando a partição da $\alpha$-lc em PEG 1000 e citrato tripotássico, corroboram os resultados anteriores.

Os trabalhos acima avaliaram a influência da temperatura apenas na partição de proteínas do soro. Chen ${ }^{39}$ mostra que o controle da temperatura possui potencial para auxiliar também nas etapas de separação da fração lipídica do soro, utilizando PEG 8000 e fosfato de potássio para concentração das proteínas do soro do leite na fase leve (polimérica) e glóbulos de gordura residuais na fase pesada. As temperaturas de $7{ }^{\circ} \mathrm{C}, 25^{\circ} \mathrm{C}$ e $40{ }^{\circ} \mathrm{C}$ foram avaliadas. A menor temperatura, utilizando $11,7 \%$ de PEG, $10 \%$ de fosfato de potássio e $\mathrm{pH} 3,8$ apresentou melhor resultado de remoção da fase lipídica (98\%) e melhor recuperação das proteínas do soro leite (> $90 \%)$.

Um fator relevante e muitas vezes desconsiderado é a influência da adição do soro do leite sobre a curva binodal de sistemas polímero-sal utilizados. O entendimento deste efeito é importante para definição de condições operacionais e não deve ser negligenciado. Alguns autores, como Rito-Palomares e Hernandez ${ }^{40}$, Rito-Palomares e Cueto ${ }^{71}$ e Perumalsamy e Thanabalan ${ }^{48}$ abordam o assunto e sugerem que os principais interferentes são a fração lipídica e alto teor de sal presente no soro de queijo..$^{40,48,71}$ Perumalsamy e Thanabalan ${ }^{48}$ também estudaram a influência da temperatura $\left(25,35\right.$ e $\left.45^{\circ} \mathrm{C}\right)$ dentro deste contexto, utilizando PEG 2000 e citrato de sódio. Os resultados demonstram que em menores temperaturas o deslocamento da curva binodal é mais acentuado.

Independente da adição do soro, a temperatura também afeta o diagrama de equilíbrio das fases do processo, onde é possível observar mudanças no comprimento e inclinação das linhas de amarração. Em temperaturas inferiores a $20^{\circ} \mathrm{C}$, a curva binodal desloca-se em direção às baixas concentrações dos componentes que formam as fases, resultando em aumento do comprimento das linhas de amarração. Sistemas próximos a composição do ponto crítico são mais influenciados pela mudança de temperatura, devido à sua instabilidade. Quando a curva binodal é deslocada, o sistema pode atingir facilmente a região monofásica. ${ }^{72,73}$ Belval et al..$^{74}$ avaliaram a influência da temperatura sobre a formação de SAB's próximos de seu ponto crítico, utilizando PEG e sal como componentes das fases e diferentes proteínas, dentre elas a BSA. É demonstrado que o controle da temperatura permite a formação de sistemas bifásicos muito perto de seu ponto crítico.

Outro fator relevante é a estabilidade térmica das proteínas do soro nas fases utilizadas, uma vez que essa estabilidade pode ser influenciada pela adição de sal e cosolventes. ${ }^{75}$ Apesar da carência de trabalhos específicos, que relacionam a estabilidade térmica de proteínas em fases utilizadas em SAB's, que neste caso são compostas por três componentes (água, polímero e sal), é possível fazer uma análise com base em trabalhos paralelos.

Os ânions citrato e fosfato são predominantes nas fases salinas utilizadas nos trabalhos apresentados na Tabela 1, referentes aos sistemas polímero-sal. Ambos apresentam as qualidades necessárias para a utilização em SAB's em escala industrial; (i) baixo custo; (ii) estabilidade para formação de fases; (iii) e vasta caracterização do sistema bifásico disponível na literatura. Em função de problemas ambientais relacionados a dificuldade de tratamento de águas residuárias com alta concentração de fosfatos, pesquisas apresentando a utilização do ânion citrato em SAB's vem ganhando destaque, por sua baixa toxicidade e boa degradabilidade..$^{55,76}$

A estabilidade térmica das proteínas está diretamente relacionada à concentração dos sais utilizados. Em baixas concentrações, até $1 \mathrm{~mol} \cdot \mathrm{L}^{-1}$, a neutralização eletrostática favorece a estabilização das proteínas, em detrimento do tipo de sal utilizado. Em concentrações superiores, utilizadas nas fases salinas dos SAB's, a influência dos sais sobre a estabilidade proteica normalmente obedece a série de Hofmeister.

Citrato $^{3-}>$ Sulfato $^{2-}>$ Fosfato $^{2-}>\mathrm{F}^{-}>\mathrm{Cl}^{-}>\mathrm{Br}^{-}>\mathrm{I}^{-}>$ $\mathrm{NO}_{3}^{-}>\mathrm{ClO}_{4}^{-}$ 
Ânions como o fosfato, citrato e sulfato são capazes de estabilizar as estruturas proteicas em função de sua habilidade de se ligar fracamente às proteínas e aumentar sua hidratação, enquanto ânions opostos pela série de Hofmeister são desestabilizantes. ${ }^{77}$

A variação da estabilidade térmica das proteínas do soro do leite em relação a concentração salina é citada por diferentes autores. Damodaran ${ }^{78}$ avaliou a estabilidade térmica da $\beta$-lc em diferentes sais a base de sódio. Seus resultados mostram que a variação da estabilidade térmica seguiu a série de Hofmeister, apresentando resultados onde a temperatura de desnaturação da proteína aumenta $\left(\mathrm{Na}_{2} \mathrm{SO}_{4}, \mathrm{NaCl}\right.$ e $\left.\mathrm{NaBr}\right)$ e diminui $\left(\mathrm{NaClO}_{4}, \mathrm{NaSCN}\right.$, ureia). Resultados que são corroborados por outros trabalhos que avaliaram a estabilidade térmica das proteínas do soro em soluções salinas. ${ }^{79,80}$

Apesar dos resultados convergirem até o momento, não é possível generalizar o efeito da concentração salina sobre a estabilidade térmica, visto que as diferentes estruturas das proteínas do soro também é um fator relevante. O mesmo trabalho de Damodaran ${ }^{78}$ que demostrou que a $\beta$-lc seguia a série de Hofmeister para explicar a variação da temperatura de desnaturação em função da concentração salina, apresentou resultados contrários para a BSA, seguindo a ordem inversa da série.

\subsection{SAB's Polímero - Polímero}

Em comparação com o sistema polímero-sal, o sistema polímero-polímero apresenta as vantagens de provocar menores alterações estruturais nas proteínas e usar compostos que facilitam a regeneração das fases utilizadas. ${ }^{81,82}$ Por outro lado, o alto custo de alguns polímeros utilizados (ex.: dextrana) inviabiliza economicamente sua utilização em grande escala, o que estimula pesquisas em busca de polímeros alternativos. ${ }^{81,83-85}$ É possível encontrar na literatura a utilização de polímeros como a dextrana, ${ }^{15,86,87}$ arabinogalactano ${ }^{25,28}$ e maltodextrina ${ }^{27,29}$ aplicados em conjunto com o PEG para partição de proteínas do soro do leite como sintetizado na Tabela 2.

PEG é o polímero mais popular usado em SAB's. Trabalhos reportam que o PEG é não tóxico, biodegradável e não possui a capacidade de alterar significantemente as propriedades das proteínas ou provocar mudanças estruturais. ${ }^{23}$ Uma pesquisa mais profunda revela que existem alguns resultados contrários e pouca informação publicada a respeito dos mecanismos de interação entre o PEG e proteínas globulares, como as do soro do leite.

Settu et al ${ }^{88}$ avaliaram a influência da temperatura $(0,30$ e $40{ }^{\circ} \mathrm{C}$ ) na partição da BSA, utilizando PEG de diferentes massas molares (4000, 6000 e 10000) e poli(ácido acrílico). Os resultados mostram que o coeficiente de partição tende a diminuir com o incremento da temperatura em todas as massas molares avaliadas. De acordo com os autores, o incremento da temperatura afeta o PEG estendendo sua estrutura e por consequência desfavorecendo a interação entre a proteína e o polímero. Explicação que está em concordância com outros autores que avaliaram a partição de proteínas em sistemas utilizando PEG e poli(ácido acrílico). ${ }^{85}$

Visando o desenvolvimento de sistemas alternativos e de baixo custo, Sarubbo et al. ${ }^{89}$ avaliaram duas temperaturas $\left(25\right.$ e $40{ }^{\circ} \mathrm{C}$ ) na partição da BSA, utilizando PEG 1500 e uma goma ácida composta de heteropolissacárideos derivada da árvore do caju. Os resultados mostram que a BSA se concentrou na fase inferior, composta pela goma e o incremento da temperatura afetou negativamente o coeficiente de partição da proteína. Os autores observaram que as composições das fases não mudaram em função do incremento da temperatura, sugerindo que a mudança no coeficiente de partição pode estar relacionada a outros fatores, como as interações eletrostáticas e hidrofóbicas, e mudanças conformacionais.

Sawant et al..$^{90}$ observaram a influência da temperatura (5, 12 e $22^{\circ} \mathrm{C}$ ) na partição da mesma proteína (BSA), utilizando o PEG 8000 e dextrana. Foi registrado um aumento do coeficiente de partição com a elevação da temperatura. Nota-se a utilização de temperaturas relativamente baixas, em relação às temperaturas ótimas dos experimentos anteriormente citados, portanto ficam pendentes elucidações futuras quanto ao comportamento particional do sistema acima da temperatura de $22{ }^{\circ} \mathrm{C}$.

Diferentes autores reportam a diminuição da estabilidade térmica de proteínas em função da interação com o polímero PEG, principalmente em função do aumento da concentração do polímero e diminuição da massa molar. ${ }^{91-94}$ De acordo com Lee e Lee ${ }^{95}$ (1987), foi observada a diminuição da temperatura de desnaturação da $\beta$-lc em função da interação com o PEG. Os autores sugerem uma relação linear entre a diminuição da temperatura e a maior hidrofobicidade das proteínas. Dentre as proteínas avaliadas, a $\beta$-lc apresentou maior diminuição da temperatura de desnaturação em função de sua maior hidrofobicidade. Em

Tabela 2. Efeito da temperatura na separação de proteínas do soro do leite em SAB's

\begin{tabular}{cccccc}
\hline \multicolumn{7}{c}{ Polímero - Polímero } \\
\hline Proteínas & Componentes & T $\left({ }^{\circ} \mathbf{C}\right)$ & Efeito $\uparrow \mathbf{T}$ & pH & Referências \\
\hline BSA & PEG $(4000$, 6000 e 10000) e poli(ácido acrílico) & $0,30,40$ & $\downarrow \mathrm{K}$ & 8,0 & 88 \\
BSA & PEG 1500 e goma ácida & 25 e 40 & $\downarrow \mathrm{K}$ & 7,0 & 89 \\
BSA & PEG 8000 e dextrana & 5,12 e 22 & $\uparrow \mathrm{K}$ & 7,0 & 90 \\
\hline
\end{tabular}

Legenda: $\kappa$ : Coeficiente de Partição; T: Temperatura; $\uparrow:$ Aumento; $\downarrow$ :Diminuição. 
altas temperaturas o PEG 1000 interage preferencialmente com a forma desnaturada da $\beta$-lc, resultado que é consistente com a alta hidrofobicidade do PEG e sua possível interação com os resíduos hidrofóbicos expostos da proteína em função da temperatura. Farruggia et al. ${ }^{96}$ (1999) observaram um aumento da temperatura de desnaturação da BSA em função da interação com o PEG 8000 e 3500, enquanto que para o PEG 1000 apresentou diminuição da temperatura de desnaturação.

\subsection{Líquido iônico - Sal}

Muitos dos polímeros utilizados nos SAB's mencionados até agora apresentam alta viscosidade e formam soluções geralmente opacas, propriedades que interferem nas técnicas de análises instrumentais usadas na quantificação das proteínas extraídas. ${ }^{97,98}$ Recentemente, a utilização de líquidos iônicos em substituição das fases poliméricas vem se destacando nos processos de separação de proteínas do soro do leite e se apresenta como uma área de pesquisa em crescimento. ${ }^{45,46}$ Líquidos iônicos são sais compostos por íons de dimensões distintas, que não formam uma rede cristalina bem definida e, consequentemente, permanecem líquidos à temperatura ambiente. Se diferem dos sais comuns por apresentar uma fraca interação inter-iônica, resultando em uma baixa energia do retículo cristalino e baixa temperatura de fusão. ${ }^{42}$

De acordo com Freire ${ }^{99}$, o coeficiente de partição das proteínas em um SAB's que utiliza líquido iônicos, pode ser afetado por diversos fatores, como os componentes e composição das fases, $\mathrm{pH}$ e temperatura do sistema. A temperatura por sua vez, pode afetar o coeficiente de partição das proteínas através das mudanças na composição e propriedades das fases e também modificando a carga e propriedades de superfície das proteínas. ${ }^{99}$ Logo, é importante entender como os líquidos iônicos se comportam diante das variações da temperatura. Rios e Fernandez ${ }^{100}$ relatam importantes propriedades termofísicas dos líquidos iônicos, como as temperaturas de fusão, solidificação, transição vítrea e cristalização. Apresentam também a influência da temperatura sobre as propriedades ópticas dos líquidos iônicos.

Como a síntese de alguns LI é complexa e possui alto custo e, além disso, vários desses LI são tóxicos e pouco degradáveis, ${ }^{6}$ pesquisas envolvendo solventes eutéticos profundos (SEP's) vem sendo desenvolvidas?. OS SEP's vêm sendo estudados, devido à semelhança em propriedades físicas com LI, com vantagens superiores como volatividade insignificante, não-inflamabilidade, biodegradabilidade e baixa toxicidade. ${ }^{6}$ Os SEP's são formados por uma mistura eutética por aceitadores de ligações de hidrogênio e doadores de ligação de hidrogênio. ${ }^{6,101}$

Muitos dos trabalhos publicados utilizam proteínas modelos, em especial a proteína do soro do leite BSA. O mecanismo que rege a partição das proteínas em um SAB's que utiliza líquidos iônicos é complexo e ainda não é completamente compreendido. Pang et al. ${ }^{6}$ estudaram a aplicação de SAB's baseados em SEP's e sais na extração de BSA. Os autores encontraram elevadas eficiências de extração para a proteína (até 95,6\%). A eficiência de extração da BSA aumentou até uma temperatura de $25^{\circ} \mathrm{C}$. Acima deste valor, observou-se uma diminuição nos valores de eficiência gradualmente até $55^{\circ} \mathrm{C}$. De acordo com os autores, $\mathrm{o}$ aumento da temperatura promove uma diminuição na viscosidade do SEP, e aumenta a capacidade de difusão das proteínas. No entanto, temperaturas elevadas podem inibir a interação proteína e água, prejudicando a extração. ${ }^{6}$

Pesquisas realizadas visando analisar o efeito da temperatura na separação de proteínas do soro de leite em sistemas SAB's Líquido iônico - Sal são apresentadas na Tabela 3.

Ding et al. ${ }^{104}$ investigaram a influência da temperatura na partição de diversas proteínas, dentre elas a BSA, utilizando líquido iônico baseado em guanidinium e fosfato de sódio. Seus resultados mostram que a eficiência máxima de extração da BSA (97\%) é atingida em $25^{\circ} \mathrm{C}$, tendendo a diminuir com o incremento da temperatura. Os autores sugerem que as interações hidrofóbicas aumentam com o incremento da temperatura até os $25^{\circ} \mathrm{C}$, favorecendo a partição da proteína. Em temperaturas superiores, a energia é suficiente para quebrar as ligações de hidrogênio entre a água superficial e os resíduos de aminoácidos, enfraquecendo o efeito hidrofóbico e diminuindo a eficiência de extração. Em temperaturas superiores a $65^{\circ} \mathrm{C}$ as proteínas se apresentam desnaturadas e a eficiência de extração é de $0 \%$.

Chen et $a l .{ }^{43}$ avaliaram o efeito da temperatura sobre a eficiência de extração da BSA em SAB's utilizando propionato de N,N-dimetiletanolamina e fosfato de potássio. Foi observado que o incremento da temperatura de 15 para $25{ }^{\circ} \mathrm{C}$ causou um aumento da eficiência de

Tabela 3. Efeito da temperatura na separação de proteínas do soro do leite em SAB's Líquido Iônico - Sal

\begin{tabular}{lccccc}
\hline \multicolumn{4}{c}{ Líquido Iônico - Sal } & & \\
\hline Proteínas & Componentes & T $\left({ }^{\mathbf{C}} \mathbf{C}\right)$ & Efeito $\uparrow \mathbf{T}$ & pH & Referências \\
\hline BSA & Cloreto 1-butil-3-metilimidazó-lio e fosfato de potássio & $25-70$ & $\mathrm{~K}$ cte & - & 102 \\
BSA & Imidazólio e fosfato de potássio & $5-45$ & $\uparrow \mathrm{K}$ & 9,3 & 103 \\
BSA & Guanidinium e fosfato de sódio & $15-75$ & $\downarrow \mathrm{K}$ & - & 104 \\
BSA & Propionato de N,N-dimetileta-nolamina e fosfato de potássio & $15-70$ & $\downarrow \mathrm{K}$ & - & 43 \\
$\alpha$-lc & Cloreto 1-etil-3-metilimidazólio e fosfato de potássio & $20,30,40$ e 50 & $\uparrow \mathrm{K}$ & 7,5 & 105 \\
\hline
\end{tabular}

Legenda: K: Coeficiente de Partição; T: Temperatura; $\uparrow:$ Aumento; $\downarrow$ :Diminuição; cte: Constante. 
extração de $86,59 \%$ para $99,24 \%$. Segundo os autores, o aumento da temperatura de extração reduz a viscosidade do líquido iônico, uma das fases do sistema de extração, aumentando a capacidade de difusão da proteína. A partir de $30^{\circ} \mathrm{C}$ observou-se progressiva diminuição da eficiência de extração, em concordância com os resultados apresentados por Ding et al. ${ }^{104}$

A influência da temperatura sobre o diagrama de fases de SAB's que utilizam líquidos iônicos também é um fator relevante. Du et al. ${ }^{102}$ estudaram o efeito da temperatura $\left(25-70{ }^{\circ} \mathrm{C}\right)$ sobre a eficiência de extração da BSA, utilizando cloreto 1-butil-3-metilimidazólio e fosfato de potássio. Observaram que até $60^{\circ} \mathrm{C}$ a eficiência de extração da proteína era praticamente constante, porém com o incremento da temperatura, maiores concentrações do líquido iônico e sal eram necessárias para manter o SAB's. Em temperaturas superiores a eficiência caiu bruscamente, devido a mudanças estruturais da proteína.

Pei et al. ${ }^{103}$ decidiram manter a faixa de temperatura para o estudo da eficiência de extração do BSA entre 15 e $45^{\circ} \mathrm{C}$, pois também constataram dois estágios de desnaturação da proteína em temperaturas acima de $60{ }^{\circ} \mathrm{C}$, assim como Du et al. ${ }^{102} \mathrm{O}$ primeiro a $62{ }^{\circ} \mathrm{C}$ de caráter reversível e o segundo a $65{ }^{\circ} \mathrm{C}$ de caráter irreversível. Utilizando imidazólio e fosfato de potássio, o coeficiente de partição aumentou em função do incremento da temperatura.

Em contraste aos outros trabalhos apresentados, Sampaio et al. ${ }^{105}$ apresentam a utilização de líquidos iônicos para uma proteína diferente da BSA, a $\alpha$-lc. O incremento da temperatura $\left(20,30,40\right.$ e $\left.50{ }^{\circ} \mathrm{C}\right)$ favoreceu o aumento do coeficiente de partição, utilizando cloreto 1-etil-3-metilimidazólio e fosfato de potássio. Assim como Pei et al. ${ }^{103}$, os autores evitaram temperaturas onde aconteceriam mudanças irreversíveis na proteína.

Diante de tantos trabalhos que mostram a perda de estrutura das proteínas, se torna importante estudos mais profundos a respeito da estabilidade térmica das proteínas em diferentes líquidos iônicos e condições testadas. Quental et al. ${ }^{106}$ utilizaram líquidos iônios baseados em colina e poli(propilenoglicol) para extração de BSA. Apesar de não ter avaliado o efeito da temperatura na eficiência de extração, os autores avaliaram o efeito da temperatura na estrutura da BSA solubilizada em acetato de colina, através de análises de espectroscopia de infravermelho com transformada de Fourier. Os resultados mostram que não existem mudanças significativas nas estruturas secundárias da BSA em temperaturas abaixo de $55^{\circ} \mathrm{C}$. A partir desta temperatura é possível observar desvios no pico I relacionado ao grupo funcional amida, caracterizando perda de estrutura secundária em função do incremento da temperatura, em concordância com os resultados apresentados por Du et al. ${ }^{102}$

Outros fatores, além da temperatura, podem afetar as estruturas proteicas das proteínas do soro do leite em SAB's que utilizam de líquidos iônicos. Desai et al. ${ }^{107}$ mostram que a concentração dos líquidos iônicos testados (Iolilyte 221PG e Cyphos 108) influência diretamente na estabilidade da BSA. Se considerarmos a concentração mínima necessária para formação das duas fases e a concentração máxima para que não ocorra agregação das proteínas, a faixa de concentração para utilização é estreita.

Pode-se concluir que, assim como nas fases polímero-sal e polímero-polímero, apesar da possibilidade da otimização do processo de extração das proteínas através do incremento da temperatura, é necessário avaliar a estabilidade térmica e a relação dessa estabilidade com outros fatores, como por exemplo a concentração de liquido iônico, visando a preservação das propriedades funcionais e atividade biológica das proteínas.

É possível encontrar na literatura trabalhos em que a utilização dos líquidos iônicos aumentaram a estabilidade térmica das proteínas. ${ }^{108-111}$ Taha et al. ${ }^{47}(2015)$ investigaram a estabilidade térmica de diferentes SAB's utilizados na partição da BSA. Sistema composto por tampões de Good (soluções tampão ideais para investigação em Biologia e Bioquímica), líquido iônico e PEG 400 apresentaram incremento de sua estabilidade térmica $\left(59^{\circ} \mathrm{C}\right)$. Ajaj ${ }^{12}$ (2010) avaliou o efeito da concentração do cloreto de colina sobre a estabilidade térmica da $\alpha$-lc. Os resultados mostram que em baixas concentrações, o líquido iônico favorece uma leve desnaturação da proteína, enquanto em altas concentrações o efeito estabilizante é evidente.

\section{Partição por Indução Térmica}

Uma desvantagem do processo de separação por SAB's é a dificuldade de separar as proteínas das soluções poliméricas que promovem a partição. Outra questão é a necessidade de métodos mais baratos que os usuais (ex. ultrafiltração e cromatográficos) para a reciclagem destas fases poliméricas e assim melhorar a relação custo benefício do processo. A partição de fases poliméricas por indução térmica possui potencial para resolver esses problemas. ${ }^{113} \mathrm{Um}$ exemplo são os polímeros lineares não iônicos compostos de PEG, que normalmente são solúveis em água mas separam fases quando aquecidos a temperaturas específicas. A temperatura em que a transição ocorre é chamada de ponto de nuvem do polímero. A partição de fases poliméricas por indução térmica pode ser usada combinada a processos de SAB's para separação e purificação de proteínas, fato relatado em diversos trabalhos publicados. ${ }^{113-120}$

Johansson et al. ${ }^{118}$ demostram que proteínas podem ser separadas em um sistema composto de apenas uma fase polimérica e água. A fase polimérica é composta por óxido de etileno e grupos de óxido de propileno hidrofobicamente modificados, cujo ponto de nuvem é $14{ }^{\circ} \mathrm{C}$. A partição de três proteínas, dentre elas a BSA, em sistemas água/polímero foram estudadas. Em temperaturas acima do seu ponto de nuvem $\left(17-30^{\circ} \mathrm{C}\right)$ é percebida a separação das fases, onde a fase superior é composta praticamente apenas por água e a fase inferior pela fase polimérica em concentração entre 
5-9\%. Os resultados mostram que alterando parâmetros como o $\mathrm{pH}$, força iônica e temperatura, é possível que a BSA seja particionada tanto para a fase aquosa quanto a polimérica, reforçando o potencial para o fracionamento de proteínas que o método possui.

A fase polimérica usada pode ser derivada de um SAB's para separação prévia das proteínas, onde a técnica demonstrada por Johansson et al. ${ }^{118}$ é utilizada para que as proteínas antes presentes na fase polimérica migrem para uma fase aquosa, onde podem ser separadas mais facilmente através de métodos como a secagem. A fase polimérica pode ser então regenerada para uma nova extração. É possível encontrar na literatura outros trabalhos semelhantes que utilizaram polímeros termo-responsivos para a separação de proteínas do soro do leite, como a $\alpha$-lc, $\beta$-lc e também a BSA. ${ }^{118,121,122}$

Recentemente, uma derivação dos SAB's, o processo de flotação em sistema aquoso de duas fases vem sendo empregado em diversas áreas com intuito de purificação de biomoléculas. A extração é baseada no transporte de massa entre as fases aquosas e adsorção nas bolhas geradas. ${ }^{123}$ Jiang et al. aplicou a flotação em sistemas aquosos de duas fases usando polímero termo responsivo (poli(etilenoglicolran-propilenoglicol)) e fosfato de potássio monobásico para separação de $\alpha$-lc diretamente do soro do leite. ${ }^{124} \mathrm{O}$ trabalho mostra uma faceta atual (2021) do que aparece de mais atual envolvendo sistemas aquosos bifásicos e polímeros termo responsivos, aplicado a separação de proteínas do soro do leite.

\section{Conclusão}

A exposição dos trabalhos citados reafirma a relevância tecnológica da extração por SAB's, e sua versatilidade de aplicação para a extração de componentes proteicos do leite como BSA, Proteínas do Soro, GMP, $\alpha$-lc e $\beta$-lg. Além disso, a temperatura se confirma variável de importante controle no projeto e execução dessas extrações, alterando os índices de eficiência de extração.

Para SAB's de composição Polímero-Sal a extração de BSA apresentou em dois trabalhos citados diminuição da eficiência com elevação de temperatura quando utilizou-se PEG (2000 e 6000) e citrato de sódio. Porém, quando o PEG 4000 foi utilizado com o mesmo sal, houve elevação da eficiência do processo, evidenciando a necessidade de testes com PEG's de outros massas moleculares, para melhor conclusão. Na análise da extração de proteínas do soro do leite pode-se observar que, ao utilizar PEG's de menor peso molecular (2000 e 4000) o aumento da temperatura levou a uma diminuição da eficiência do processo de extração, inverso do constatado ao utilizar PEG 8000. Para proteínas GMP, $\alpha$-lc e $\beta$-lc a elevação da temperatura resultou em aumento da eficiência, utilizando PEG's de baixa massa molecular ou PVP como polímeros, e como sais o citrato de sódio e fosfato de potássio. Para essas proteínas o resultado foi contrário apenas quando o sal utilizado foi o citrato tripotássico.

Para SAB's de composição Polímero-Polímero os testes de extração de BSA evidenciaram tendência de diminuição da eficiência com elevação da temperatura utilizando PEG's de diferentes massas moleculares com poli(ácido acrílico) ou goma ácida, apresentando resultado contrário apenas na associação PEG 8000 e dextrana.

Para SAB's de composição Líquido Iônico-Sal os estudos apresentaram resultados ímpares para a relação temperatura e eficiência na extração de BSA. Dependendo da composição das fases constatou-se elevação, diminuição ou até constância de eficiência para diferentes temperaturas. Para a proteína $\alpha$-lc foi observada elevação da eficiência com o aquecimento do sistema.

\section{Referências Bibliográficas}

1. Freire, L. A. C.; Pereira, C. G.; Partition of $\alpha$-lactoalbumin and $\beta$-lactoglobulin from goat milk whey utilizing aqueous biphasic systems. Separation Science and Technology 2016, 51, 457. [CrossRef]

2. González-Amado, M.; Tavares, A. P. M.; Freire, M. G.; Soto, A.; Rodríguez, O.; Recovery of lactose and proteins from cheese whey with poly(ethylene)glycol/sulfate aqueous two-phase systems. Separation and Purification Technology 2020, 255, 117686. [CrossRef]

3. Metsämuuronen, S.; Mänttäri, M.; Nyström, M.; Comparison of analysis methods for protein concentration and its use in UF fractionation of whey. Desalination 2011, 283, 156. [CrossRef]

4. Ramos, O. L.; Pereira, R. N.; Martins, A.; Rodrigues, R.; Fuciños, C.; Teixeria, J. A.; Pastrana, L.; Malcata, X. F.; Vicente, A. A.; Design of whey protein nanostructures for incorporation and release of nutraceutical compounds in food. Critical Reviews in Food Science and Nutrition 2017, 57, 1377. [CrossRef]

5. Madureira, A. R.; Tavares, T.; Gomes, A. M. P.; Pintado, M. E.; Malcata, F. X. Invited review: Physiological properties of bioactive peptides obtained from whey proteins. Journal of Dairy Science 2010, 93, 437. [CrossRef]

6. Pang, J; Sha, X.; Chao, Y.; Chen, G.; Han, C.; Zhu, W.; Li, H.; Zhang, Q.; Green aqueous biphasic systems containing deep eutectic solvents and sodium salts for the extraction of protein. RSC Advances 2017, 7, 49361. [CrossRef]

7. Cheison, S. C.; Leeb, E.; Toro-Sierra, J.; Kulozik, U.; Influence of hydrolysis temperature and $\mathrm{pH}$ on the selective hydrolysis of whey proteins by trypsin and potential recovery of native alpha-lactalbumin.International Dairy Journal 2011, 21, 166. [CrossRef]

8. Corrochano, A. R.; Buckin, V.; Kelly, P. M.; Giblin, L.; Invited review: Whey proteins as antioxidants and promoters of cellular antioxidant pathways. Journal of Dairy Science 2018, 101, 4747. [CrossRef]

9. Bogahawaththa, D.; Chandrapala, J.; Vasiljevic, T.; Thermal denaturation of bovine immunoglobulin $\mathrm{G}$ and its association with other whey proteins. Food Hydrocolloids 2017, 72, 350. [CrossRef] 
10. Pizones Ruiz-Henestrosa, V. M.; Martinez, M. J.; Carrera Sánchez, C.; Rodríguez Patino, J. M.; Pilosof, A. M. R.; Mixed soy globulins and $\beta$-lactoglobulin systems behaviour inaqueous solutions and at the air-water interface. Food Hydrocolloids 2014, 35, 106. [CrossRef]

11. Nicolai, T.; Britten, M.; Schmitt, C.; $\beta$-Lactoglobulin and WPI aggregates: Formation, structure and applications. Food Hydrocolloids 2011, 25, 1945. [CrossRef]

12. Pires, A. F.; Marnotes, N. G.; Rubio, O. D.; Garcia, A. C.; Pereira, C. D.; Dairy By-Products: A Review on the Valorization of Whey and Second Cheese Whey. Foods 2021, 10, 1067. [CrossRef]

13. Bylund, G.; Dairy processing handbook, 2a. ed., Tetra Pak: Switzerland, 1995.

14. Bonnaillie, L. M.; Tomasula, P. M.; In Whey Processing, Functionality and Health Benefits; Onwulata, C. I.; Huth, P. J., eds.; Wiley: New Jersey, 2008, cap. 2. [CrossRef]

15. Alcântara, L. A. P.; Amaral, I. V.; Bonomo, R. C. F.; Silva, L. H. M.; Silva, M. C. H.; Minim, V. P. R.; Minim, L. A.; Partitioning of $\alpha$-lactalbumin and $\beta$-lactoglobulin from cheese whey in aqueous two-phase systems containing poly (ethylene glycol) and sodium polyacrylate. Food and Bioproducts Processing 2014, 92, 409. [CrossRef]

16. Mohan, P. M.; Shamnamol G. K.; Extraction of Cheese Whey Protein from Dairy Effluent by Using Polyethylene Glycol and Sodium Sulphate. International Journal of Innovative Research in Science, Engineering and Technology 2015, 4, 868. [CrossRef]

17. Iqbal, M.; Tao, Y.; Xie, S.; Zhu, Y.; Chen, D.; Wang, X.; Huang, L.; Peng, D.; Sattar, A.; Shabbir, M. A. B.; Hussain, H. I.; Ahmed, S.; Yuan, Z.; Aqueous two-phase system (ATPS): an overview and advances in its applications. Biological Procedures Online 2016, 18, 1. [CrossRef]

18. Geankoplis, C. J.; Transport processes and unit operations, 2a. ed., Longman Higher Education: London, 1983.

19. Silva, L. H. M.; Loh, W.; Sistemas aquosos bifásicos: fundamentos e aplicações para partição/purificação de proteínas. Química Nova 2006, 29, 1345. [CrossRef]

20. Su, C. K.; Chiang, B. H.; Partitioning and purification of lysozyme from chicken egg white using aqueous two-phase system. Process Biochemistry 2006, 41, 257. [CrossRef]

21. Schmidt, A. S.; Ventom, A. M.; Asenjo, J. A.; Partitioning and purification of $\alpha$-amylase in aqueous two-phase systems. Enzyme and Microbial Technology 1994, 16, 131. [CrossRef]

22. Silva, L. H. M.; Loh, W.; Sistemas aquosos bifásicos: fundamentos e aplicações para partição/purificação de proteínas. Química Nova 2006, 29, 1345. [CrossRef]

23. Zaslavsky, B. Y.; Aqueous two-phase partitioning: physical chemistry and bioanalytical applications, 1a. ed., CRC Press: Florida, 1994. [CrossRef]

24. Zuniga, A. D. G.; Coimbra, J. S. R.; Teixeira, J.; Rodrigues, L.; In Engineering Aspects of Milk and Dairy Products; Coimbra, J. S. R.; Teixeira, J. A., eds.; CRC Press: Florida, 2009, cap. 4.

25. Ng, T.; Lay, M. C.; Swan, J. E.; Chemeca, Perth, Western Australia, 2014. [Link]

26. Rojas, E. E. G.; Coimbra, J. S. R.; Minim, L. A.; Zuniga, A. D. G.; Saraiva, S. R.; Minim, V. P. R.; Size-exclusion chromatography applied to the purification of whey proteins from the polymeric and saline phases of aqueous two-phase systems. Process Biochemistry 2004, 39, 1751. [CrossRef]

27. Anandharamakrishnan, C.; Raghavendra, S. N.; Barhate, R. S.; Hanumesh, U.; Raghavarao, K. S. M. S.; Aqueous two-phase extraction for recovery of proteins from cheese whey. Food and Bioproducts Processing 2005, 83, 191. [CrossRef]

28. Christian, T. J.; Manley-Harris, M.; Richards, G. N.; A preliminary study of the use of larch arabinogalactan in aqueous two-phase systems. Carbohydrate Polymers 1998, 35, 7. [CrossRef]

29. Da Silva, L. M.; Meirelles, A. A.; Bovine Serum Albumin, $\alpha$-lactoalbumin and $\beta$-lactoglobulin partitioning in polyethylene glycol/maltodextrin aqueous-two-phase systems. Carbohydrate Polymers 2000, 42, 279. [CrossRef]

30. Anandharamakrishnan, C.; Raghavendra, S. N.; Barhate, R. S.,; Hanumesh, U.; Raghavarao, K. S. M. S.; Aqueous Two-Phase Extraction For Recovery Of Proteins From Cheese Whey. Food and Bioproducts Processing 2017, 83, 191. [CrossRef]

31. Capezio, L.; Romanini, D.; Picó, G. A.; Nerli, B.; Partition of whey milk proteins in aqueous two-phase systems of polyethylene glycol-phosphate as a starting point to isolate proteins expressed in transgenic milk. Journal of Chromatography B 2005, 819, 25. [CrossRef]

32. Da Silva, C. A. S.; Coimbra, J. S. dos R.; Rojas, E. E. G.; Teixeira, J. A. C.; Partitioning of glycomacropeptide in aqueous two-phase systems. Process Biochemistry 2009, 44, 1213 [CrossRef]

33. Kalaivani, S.; Regupathi, I.; Continuous aqueous two-phase extraction of $\alpha$-lactalbumin from whey in conventional rotating disc contactor. Separation Science and Technology 2016, 51, 2411. [CrossRef]

34. Freire, L. A. C.; Pereira, C. G.; Aqueous Two-Phase Systems Applied to Partition Proteins from Goat Milk Whey In-Nature. Advances in Bioscience and Biotechnology 2016, 7,350. [CrossRef]

35. Dos Reis Coimbra, J.; Thömmes, J.; Kula, M. R.; Continuous separation of whey proteins with aqueous two-phase systems in a Graesser contactor. Journal of Chromatography A 1994, 668, 85. [CrossRef]

36. Mokhtarani, B.; Mortaheb, H. R.; Mafi, M.; Amini, M. H.; Partitioning of $\alpha$-lactalbumin and $\beta$-lactoglobulin in aqueous two-phase systems of polyvinylpyrrolidone and potassium phosphate. Journal of Chromatography B 2011, 879, 721. [CrossRef]

37. Zuñiga, A. D. G.; Coimbra, J. S. R.; Minim, L. A.; Partitional Coefficients of a-lactoalbumin and b-lactoglobulin in aqueous two phase systems: Influence of molecular mass. Ciencia $y$ Tecnologia Alimentaria 2001, 3, 149. [CrossRef]

38. Lu, Y.-M.; Yang, Y.-Z.; Zhao, X.-D.; Xia, C.-B.; Bovine serum albumin partitioning in polyethylene glycol (PEG)/potassium citrate aqueous two-phase systems. Food and Bioproducts Processing 2017, 88, 40. [CrossRef]

39. Chen, J. P.; Clarification of Cheese Whey by Aqueous Two-Phase Systems. Journal of Food Science 1989, 54, 1369. [CrossRef]

40. Rito-Palomares, M.; Hernandez, M.; Influence of system and process parameters on partitioning of cheese whey proteins in aqueous two-phase systems. Journal of Chromatography B: Biomedical Sciences and Applications 1988, 711, 81. [CrossRef] 
41. Costa, A. R.; Coimbra, J. S. R.; Ferreira, L. A.; Marcos, J. C.; Santos, I. J. B.; Saldaña, M. D. A.; Teixeira, J. A. C.; Partitioning of bovine lactoferrin in aqueous two-phase system containing poly(ethylene glycol) and sodium citrate. Food and Bioproducts Processing, 2015, 95, 118. [CrossRef]

42. Michel, B.; Neves, M. T.; Sousa, R. C. S.; Chagas, M. M.; Martins, B. A.; Coimbra, J. S. R.; Partição De Proteínas De Soro De Leite Em Sistemas Aquosos Bifásicos Baseados Em Líquidos Iônicos. Química Nova 2015, 38, 1148. [CrossRef]

43. Chen, J.; Wang, Y.; Zeng, Q.; Ding, X.; Huang, Y.; Partition of proteins with extraction in aqueous two-phase system by hydroxyl ammonium-based ionic liquid. Analytical Methods 2014, 6, 4067. [CrossRef]

44. Neves, M. T.; Balbueno, A. A.; Miranda, M. P.; Colosimo, D.; Sousa, R. C. S.; Dutra, G. T.; Resumos do XX Congresso Brasileiro de Engenharia Química, Florianópolis, Brasil, 2014. [Link].

45. Alvarez-Guerra, E.; Ventura, S. P. M.; Coutinho, J. A. P.; Irabien, A.; Ionic liquid-based three phase partitioning (ILTPP) systems: Ionic liquid recovery and recycling. Fluid Phase Equilibria 2014, 371, 67. [CrossRef]

46. Alvarez-Guerra, E.; Irabien, A.; Ionic liquid-based three phase partitioning (ILTPP) systems for whey protein recovery: Ionic liquid selection. Journal of Chemical Technology Biotechnology 2015, 90, 939. [CrossRef]

47. Taha, M.; Quental, M. V.; Correia, I.; Freire, M. G.; Coutinho, J. A. P.; Extraction and stability of bovine serum albumin (BSA) using cholinium-based Good's buffers ionic liquids. Process Biochemistry, 2015, 50, 1158. [CrossRef]

48. Perumalsamy, M.; Thanabalan, M.; Extraction of Cheese whey proteins ( $\alpha$-lactalbumin and b-lactoglobulin) from dairy effluents using environmentally benign aqueous biphasic system. International Journal of Chemical and Environmental Engineering 2012, 3, 1. [Link]

49. Nguyen, M. H.; Food plant effluent treatment by membrane processes. Food Australia 1999, 51, 210. [Link]

50. Fee, C. J.; Chand, A.; Capture of lactoferrin and lactoperoxidase from raw whole milk by cation exchange chromatography. Separation and Purification Technology 2006, 48, 143. [CrossRef]

51. Domínguez-Puerto, R.; Valle-Guadarrama, S.; Guerra-Ramírez, D.; Hahn-Schlam, F.; Purification and concentration of cheese whey proteins through aqueous two phase extraction. CyTA Journal of Food 2018, 16, 452. [CrossRef]

52. Pimentel, M. C. B.; Araújo, A. I.; Figueiredo, Z. M. B.; Silva, R. A.; Cavalcanti, M. T. H.; Moreira, K. A.; Filho, J. L. L.; Porto, A. L. F.;Aqueous two-phase system for citrinin extraction from fermentation broth. Separation and Purification Technology 2013, 110, 158. [CrossRef]

53. Takeuchi, K.; Fujino, M.; Suga, T.; Room temperature temporary bonding of glass substrates based on SAB method using si intermediate layer. IEEE Transactions on Components, Packaging and Manufacturing Technology 2017, 7, 1713. [CrossRef]

54. Vázquez-Villegas, P.; Aguilar, O.; Rito-Palomares, M.; Study of biomolecules partition coefficients on a novel continuous separator using polymer-salt aqueous two-phase systems. Separation and Purification Technology 2011, 78, 69. [CrossRef]

55. Perumalsamy, M.; Murugesan, T.; Partition Behavior of Bovine Serum Albumin in PEG2000-Sodium Citrate-Water Based Aqueous Two-Phase System. Separation Science and Technology 2007, 42, 2049. [CrossRef]

56. Perumalsamy, M.; Batcha, M. I.; Synergistic extraction of bovine serum albumin using polyethylene glycol based aqueous biphasic system. Process Biochemistry 2011, 46, 494. [CrossRef]

57. Muthiah, P.; Pampana, B. K.; Influence of Phase Compositions, $\mathrm{pH}$ and Temperature on Bovine Serum Albumin Partitioning in Aqueous Biphasic System. Chemical Product and Process Modeling 2010, 5, 1. [CrossRef]

58. Sivakumar, K.; Iyyaswami, R.; Recovery and Partial Purification of Bovine $\alpha$-Lactalbumin from Whey Using PEG 1000 Trisdoium Citrate Systems. Separation Science and Technology 2015, 50, 833. [CrossRef]

59. Kalaivani, S.; Regupathi, I.; Partitioning studies of $\alpha$-lactalbumin in environmental friendly poly (ethylene glycol) - Citrate salt aqueous two phase systems. Bioprocess and Biosystems Engineering 2013, 36, 1475. [CrossRef]

60. da Silva, C. A. S.; Coimbra, J. S. R.; Rojas, E. E. G.; Minim, L. A.; da Silva, L. H. M.; Partitioning of caseinomacropeptide in aqueous two-phase systems. Journal of Chromatography $B$ 2007, 858, 205. [CrossRef]

61. Walter, H.; Johansson, G.; Aqueous two-phase systems, 1st ed., Elsevier: Amsterdã, 1994. [CrossRef]

62. Hamborg, L.; Horsted, E. W.; Johansson, K. E.; Willemoës, M.; Lindorff-Larsen, K.; Teilum, K.; Global analysis of protein stability by temperature and chemical denaturation. Analytical Biochemistry 2020. [CrossRef]

63. Haque, M. A.; Aldred, P., Chen, J.; Barrow, C. J.; Adhikari, B.; Comparative study of denaturation of whey protein isolate (WPI) in convective air drying and isothermal heat treatment processes. Food Chemistry 2013, 141, 702. [CrossRef]

64. Oliveira, V. M.; Contessoto, V. G.; Silva, F. B.; Caetano, D. L. Z.; Carvalho, S. J.; Leite, V. B. P.; Effects of pH and Salt Concentration on Stability of a Protein G Variant Using CoarseGrained Models. Biophysical Journal 2018, 114, 65. [CrossRef]

65. Spelzini, D., Farruggia, B.; Picó, G.; Features of the acid protease partition in aqueous two-phase systems of polyethylene glycolphosphate: chymosin and pepsin. Journal of Chromatography $B$ 2005, 821, 60. [CrossRef]

66. Saravanan, S.; Rao, J. R.; Murugesan, T.; Nair, B. U.; Ramasami, $\mathrm{T}$.; Partition of tannery wastewater proteins in aqueous two-phase poly (ethylene glycol)-magnesium sulfate systems: effects of molecular weights and pH. Chemical Engineering Science 2007, 62, 969. [CrossRef]

67. Nerli, B., Espariz, M.; Pico, G.; Thermodynamic study of forces involved in bovine serum albumin and ovalbumin partitioning in aqueous two-phase systems. Biotechnology and Bioengineering 2001, 72, 468. [CrossRef]

68. Rodrigues, L. R.; Venâncio, A.; Teixeira, J. A.; Partitioning and separation of $\alpha$-lactalbumin and $\beta$-lactoglobulin in polyethylene glycol/ammonium sulphate aqueous two-phase systems. Biotechnology Letters 2001, 23, 1893. [CrossRef] 
69. Permyakov, E. A.; Berliner, L. J. $\alpha$-Lactalbumin: structure and function. FEBS Letters 2000, 473, 269. [CrossRef]

70. Permyakov, E. A.; Alpha -lactalbumin, 1a. ed., Nova Science Publishers: New York, 2005. [CrossRef $]$

71. Rito-Palomares, M.; Cueto, L.; Effect of biological suspensions on the position of the binodal curve in aqueous two-phase systems. Journal of Chromatography B: Biomedical Sciences and Applications 2000, 743, 5. [CrossRef]

72. Bamberger, S.; Brooks, D. E.; Sharp, K. A.; Van Alstine, J. M.; Webber, T. J.; Em Partitioning in Aqueous Two-Phase System: Theory, Methods, Uses, And Applications To Biotechnology; Walter, H.; Brooks, D. E.; Fisher, D., eds.; Academic Press: Orlando, 1985, cap. 3. [CrossRef]

73. Tjerneld, F.; Johansson, G.; Aqueous two-phase systems for biotechnical use. Bioseparation 1990, 1, 255. [PubMed]

74. De Belval, S.; Le Breton, B.; Huddleston, J.; Lyddiatt, A.; Influence of temperature upon protein partitioning in poly(ethylene glycol)-salt aqueous two-phase systems close to the critical point with some observations relevant to the partitioning of particles. Journal of Chromatography B: Biomedical Sciences and Applications 1998, 711, 19. [CrossRef]

75. Murakami, S.; Hayashi, T.; Kinoshita, M.; Effects of Salt or Cosolvent Addition on Thermal Stability of a Protein: Relevance to those on Solubility of a Hydrophobic Solute in Water. The Journal of Chemical Physics 2017, 146, 055102. [CrossRef]

76. Benavides, J.; Rito-Palomares, M.; Practical experiences from the development of aqueous two-phase processes for the recovery of high value biological products. Journal of Chemical Technology and Biotechnology 2008, 83, 133. [CrossRef]

77. Arakawa, T.; Timasheff, S. N.; Mechanism of protein salting in and salting out by divalent cation salts: balance between hydration and salt binding. Biochemistry 1984, 23, 5912. [CrossRef]

78. Damodaran, S.; Influence of protein conformation on its adaptability under chaotropic conditions. International Journal of Biological Macromolecules 1989, 11, 2. [CrossRef]

79. Phillips, L. G., Yang, S.; Kinsella, J. E.; Neutral Salt Effects on Stability of Whey Protein Isolate Foams. Journal of Food Science 1991, 56, 588. [CrossRef]

80. Hussain, R., Gaiani, C., Jeandel, C., Ghanbaja, J.; Scher, J.; Combined effect of heat treatment and ionic strength on the functionality of whey proteins. Journal of Dairy Science 2012, 95, 6260. [CrossRef]

81. Saravanan, S., Reena, J. A., Rao, J. R., Murugesan, T.; Nair, B. U.; Phase equilibrium compositions, densities, and viscosities of aqueous two-phase poly(ethylene glycol) + poly(acrylic acid) system at various temperatures. Journal of Chemical \& Engineering Data 2006, 51, 1246. [CrossRef]

82. Vernau, J.; Kula, M.-R.; Extraction of proteins from biological raw material using aqueous polyethylene glycol-citrate phase systems. Biotechnology and Applied Biochemistry1990, 12, 397. [Link]

83. Gupta, V.; Nath, S.; Chand, S.; Role of water structure on phase separation in polyelectrolyte-polyethyleneglycol based aqueous two-phase systems. Polymer 2002, 43, 3387. [CrossRef]

84. Kajiuchi, T.; Shin-Ya, Y.; Nagai, H.; Fujiwara, K.; Partitioning of chicken egg white proteins in polyelectrolyte/salt aqueous two-phase systems composed of polyethyleneoxide-maleic acid copolymer and potassium phosphate. Journal of Chemical Technology and Biotechnology 2002, 77, 495. [CrossRef]

85. Saravanan, S.; Rao, J. R.; Nair, B. U.; Ramasami, T.; Aqueous two-phase poly(ethylene glycol)-poly(acrylic acid) system for protein partitioning: Influence of molecular weight, $\mathrm{pH}$ and temperature. Process Biochemistry 2008, 43, 905. [CrossRef]

86. Ortin, A.; Muiño-Blanco, M. T.; Calvo, M.; Lopez-Perez, M. J.; Cebrian-Perez, J. A.; Extraction of $\beta$-Lactoglobulin from Bovine Milk by Affinity Counter-Current Distribution in Aqueous Two-Phase System. Journal of Dairy Science 1992, 75, 711. [CrossRef]

87. Fele, L.; Fermeglia, M.; Partition coefficients of proteins in poly(ethylene glycol) + dextran + water at 298 K. Journal of Chemical \& Engineering Data 1996, 41, 331. [CrossRef]

88. Settu, S.; Velmurugan, P.; Jonnalagadda, R. R.; Nair, B. U.; Extraction of bovine serum albumin using aqueous two-phase poly (ethylene glycol)-poly (acrylic acid) system. Journal of Scientific \& Industrial Research 2015, 74, 348. [Link]

89. Sarubbo, L. A.; de Oliveira, L. A.; Figueiredo Porto, A. L., de Campos-Takaki, G. M.; Tambourgi, E. B.; Partition of proteins in aqueous two-phase systems based on cashew-nut tree gum and poly(ethylene glycol). Brazilian Archives of Biology and Technology 2004, 47, 685. [CrossRef]

90. Sawant, S. B.; Joshi, J. B.; Sikdar, S. K.; Partition coefficient of bovine serum albumin in two-phase aqueous systems. Biotechnology Techniques 1988, 2, 41. [CrossRef]

91. Zielenkiewicz, W.; Swierzewski, R.; Attanasio, F.; Rialdi, G.; Thermochemical,volumetric and spectroscopic properties of lysozyme-poly(ethylene) glycolsystem. Journal of Thermal Analysis and Calorimetry 2006, 83, 587. [CrossRef]

92. Farruggia, B.; García, G.; D’Angelo, C.; Picó, G.; Destabilization of human serum albumin by polyethylene glycols studied by thermodynamical equilibrium and kinetic approaches. International Journal of Biological Macromolecules 1997, 20, 43. [CrossRef]

93. Samanta, N.; Mahanta, D.; Hazra, S.; Kumar, G. S.; Mitra, R. K.; Short chain polyethylene glycols unusually assist thermal unfolding of human serum albumin. Biochimie 2014, 104, 81 . [CrossRef]

94. Hancock, T. J.; Hsu, J. T.; Thermal stability studies of a globular protein in aqueous poly(ethylene glycol) by 1H NMR. Biotechnology and Bioengineering 1996, 51, 410. [CrossRef]

95. Lee, L. L. Y.; Lee, J. C.; Thermal Stability of Proteins in the Presence of Poly(ethylene glycols). Biochemistry 1987, 26, 7813. [CrossRef]

96. Farruggia, B.; Nerli, B.; Di Nuci, H.; Rigatusso, R.; Picó, G.; Thermal features of the bovine serum albumin unfolding by polyethylene glycols. International Journal of Biological Macromolecules 1999, 26, 23. [CrossRef]

97. Perumalsamy, M.; Bathmalakshmi, A.; Murugesan, T.; Experiment and correlation of liquid- liquid equilibria of an aqueous salt polymer system containing PEG6000+ sodium citrate. Journal of Chemical \& Engineering Data 2007, 52, 1186. [CrossRef] 
98. Rydlewski, A. A.; Pizzo, J. S.; Manin, L. P.; Zappielo, C. D.; Galuch, M. B.; Santos, O. O.; Visentainer, J. V.; Analytical methods used for the determination of lipids in human milk: A review. Revista Virtual de Química 2020, 12, 155. [CrossRef]

99. Freire, M. G.; Ionic-Liquid-Based Aqueous Biphasic Systems: Fundamentals and Applications. Springer: Berlin, 2016). [CrossRef]

100. de Los Rios, A. P.; Fernandez, F. J. H.; Ionic Liquids in Separation Technology. Elsevier: Amsterdan, 2014. [CrossRef]

101. Freitas, C. M. P.; Sousa, R. C. S.; Dias, M. M.; Coimbra, J. S.; Extraction of Pectin From Passion Fruit Peel. Food Engineering Reviews 2020, 12, 460. [CrossRef]

102. Du, Z.; Yu, Y.; Wang, J.; Extraction of Proteins from Biological Fluids by Use of an Ionic Liquid/Aqueous Two-Phase System. Chemistry A European Journal 2007, 13, 2130. [CrossRef]

103. Pei, Y.; Wang, J.; Wu, K.; Xuan, X.; Lu, X.; Ionic liquid-based aqueous two-phase extraction of selected proteins. Separation and Purification Technology 2009, 64, 288. [CrossRef]

104. Ding, X.; Wang, Y.; Zeng, Q.; Chen, J.; Huang, Y.; Xu, K.; Design of functional guanidinium ionic liquid aqueous twophase systems for the efficient purification of protein. Analytica Chimica Acta 2014, 815, 22. [CrossRef]

105. Sampaio, V. S.; Bonomo, R. C. F.; Veloso, C. M.; Sousa, R. C. S.; Júnior, E. C. S.; Fontan, R. C. I.; Pignata, M. C.; Santos, K. A.; Gandolfi, O. R. R.; Partitioning Behavior of Lysozyme and $\alpha$-lactalbumin in Aqueous Two-Phase System Formed by Ionic Liquids and Potassium Phosphate. International Journal of Food Engineering 2017, 13, 1. [CrossRef]

106. Quental, M. V.; M. Caban, M. M. Pereira, Stepnowski, P.; Coutinho, J.A. P.; Freire, M. G.; Enhanced extraction of proteins using cholinium-based ionic liquids as phase-forming components of aqueous biphasic systems. Biotechnology Journal 2015, 10, 1457. [CrossRef]

107. Desai, R. K.; Streefland, M.; Wijffels, R. H.; Eppink, H. M.; Extraction and stability of selected proteins in ionic liquid based aqueous two phase systems. Green Chemistry 2014, 16, 2670. [CrossRef]

108. Noritomi, H.; Increase in Thermal Stability of Proteins by Aprotic Ionic Liquids, Intechopen, 2013. [CrossRef]

109. Weaver, K. D.; Vrikkis, R. M.; Van Vorst, M. P.; Trullinger, J.; Vijayaraghavan, R.; Foureau, D. M.; McKillop, I. H.; MacFarlane, D. R.; Kruegerb, J. K.; Elliott, G. D.; Structure and function of proteins in hydrated choline dihydrogen phosphate ionic liquid. Physical Chemistry Chemical Physics 2012, 14, 790. [CrossRef]

110. Kumar, A.; Venkatesu, P.; Overview of the Stability of $\alpha$-Chymotrypsin in Different Solvent Media. Chemical Reviews 2012, 112, 4283. [CrossRef]

111. Weingartner, H.; Cabrele, C.; Herrmann, C.; How ionic liquids can help to stabilize native proteins. Physical Chemistry Chemical Physics 2012, 14, 415. [CrossRef]

112. Ajaj, Y.; Dissertação de Mestrado, Ruhr-Universität Bochum, 2011. [Link]
113. Alred, P. A.; Kozlowski, A.; Harris, J. M.; Tjerneld, F.; Application of temperature-induced phase partitioning at ambient temperature for enzyme purification. Journal of Chromatography A 1994, 659, 289. [CrossRef]

114. Harris, P. A.; Karlstrom, G.; Tjerneld, F.; Enzyme purification using temperature-induced phase formation. Bioseparation 1991, 2, 237. [CrossRef]

115. Lu, M.; Albertsson, P. A.; Johansson, G.; Tjerneld, F.; Uconbenzoyl dextran aqueous two-phase systems: protein purification with phase component recycling. Journal of Chromatography $B$ : Biomedical Sciences and Applications 1996, 680, 65. [CrossRef]

116. Johansson, H. O.; Karlström, G.; Tjerneld, F.; Temperatureinduced phase partitioning of peptides in water solutions of ethylene oxide and propylene oxide random copolymers. Biochimica et Biophysica Acta (BBA) - General Subjects 1997, 1335, 315. [CrossRef]

117. Persson, J.; Johansson, H. O.; Tjerneld, F.; Purification of protein and recycling of polymers in a new aqueous two-phase system using two thermoseparating polymers. Journal of Chromatography A 1999, 864, 31. [CrossRef]

118. Johansson, H. O.; Persson, J.; Tjerneld, F.; Thermoseparating water/polymer system: A novel one-polymer aqueous twophase system for protein purification. Biotechnology and Bioengineerng 1999, 66, 247. [CrossRef]

119. Nilsson, A.; Johansson, H. O.; Mannesse, M.; Egmond, M. R.; Tjerneld, F.; Partitioning of peptide-tagged proteins in aqueous two-phase systems using hydrophobically modified micelle-forming thermoseparating polymer. Biochimica et Biophysica Acta (BBA) - Proteins and Proteomics 2002, 1601, 138. [CrossRef]

120. Jönsson, M.; Johansson, H. O.; Protein partitioning in thermoseparating systems of a charged hydrophobically modified ethylene oxide polymer. Journal of Chromatography A 2003, 983, 133. [CrossRef]

121. Monteiro, P. S.; Coimbra, J. S. R.; Minim, L. A.; de Oliveira, J. A.; da Silva, L. H. M.; Partition of $\alpha$-lactoalbumin and $\beta$-lactoglobulin by cloud point extraction. Journal of Chromatography B 2008, 867, 189. [CrossRef]

122. Berggren, K.; Johansson, H. O.; Yjerneld, F.; Effects of salts and the surface hydrophobicity of proteins on partitioning in aqueous two-phase systems containing thermoseparating ethylene oxidepropylene oxide copolymers. Journal of Chromatography A 1995, 718, 67. [CrossRef]

123. Sankaran, R.; Cruz, R. A. P.; Show, P. L.; Haw, C. Y.; Lai, S. H.; Ng, E.; Ling, T. C.; Recent advances of aqueous two-phase flotation system for the recovery of biomolecules. Fluid Phase Equilibria 2019, 501, 112271. [CrossRef]

124. Jiang, B. et al. Direct separation and purification of $\alpha$-lactalbumin from cow milk whey by aqueous two-phase flotation of thermosensitive polymer/phosphate. Journal of the Science of Food and Agriculture 2021, 101, 4173. [CrossRef] 